\title{
Categorical Effects in the Perception of Colour: Behavioral Evidence in Hue Search Method
}

\begin{abstract}
Abdulrahman Saud Al-rasheed
King Saud University, Riyadh, Kingdom of Saudi Arabia

CP (categorical perception) of colour is demonstrated by faster and/or more accurate discrimination of pair of stimuli that cross a category boundary (across-category), than two stimuli from the same category (within-category), even when the stimulus differences between the pairs of stimuli are equal. Despite a plethora of behavioural research exploring the origin and nature of colour CP, all the evidence for the $\mathrm{CP}$ of colour was derived from Roman script readers and as, to date, no studies of colour CP have been conducted on right-to-left readers in support of this theory. However, the influence of reading habits to perception has been shown in several studies (e.g., Eviatar, 1995, 1997; Farid \& Grainger, 1996; Prunet, Beland, \& Adrissi, 2000; Berent, 2002; Schwalm, Eviatar, Golan, \& Blumenfeld, 2003). It is not entirely clear how to predict the effect of habitual reading direction on $\mathrm{CP}$ of colour, but it was worth exploring to test the generality of $\mathrm{CP}$ of colour across variation of cultures and habitual reading directions. Two experiments (target detection task and grid search task) have been conducted to investigate the colour $\mathrm{CP}$, by testing participants from language, their reading direction is from right-to-left as in Arabic. Forty participants (20 men and 20 women) took part in this study. All spoke Arabic as their first language and most were undergraduate students at King Saud University. Their ages ranged from 18 to 30 years with a mean of 24.3 years $(S D=5.29)$. The result indicated that the reaction times in the between-categories condition were much faster than those in the within-category condition; this suggested that $\mathrm{CP}$ of colour was unaffected by the habitual reading directions. So that Arabic samples performed similarly as Roman script readers and the pattern of colour $\mathrm{CP}$ has been replicated, but this time, it has also been shown that the effect is independent of habitual reading direction.
\end{abstract}

Keywords: CP (categorical perception), discrimination, grid search task, target detection task

\section{Introduction}

The colour spectrum is a physical continuum, but it is perceived discontinuously, as discrete categories or segments of hues (Harnad, 1987). This is part of an effect called CP (categorical perception).

$\mathrm{CP}$ is found when a continuum is divided into categories, and when these categories appear to affect discrimination. In operational terms, $\mathrm{CP}$ can be defined by faster and/or more accurate discrimination of pair of stimuli that cross a category boundary (across-category), than two stimuli from the same category (within-category), even when the stimulus differences between the pairs of stimuli are equal. This definition of $\mathrm{CP}$ will be used throughout, and is illustrated in the classic form shown in Figure 1.

Abdulrahman Saud Al-rasheed, Ph.D., Department of Psychology, King Saud University. 


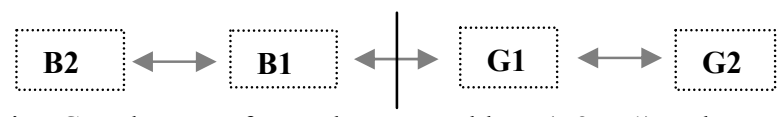

Figure 1. Diagram representing CP. There are four colours: two blues (B2, B1) and two greens (G1, G2). The arrows show the separation between adjacent pairs which are equally separated. The vertical line shows the category boundary.

Figure 1 shows four stimuli designated as B2, B1, G1, and G2. Two (B2, B1) belong to the same the linguistic category, blue, and two $(\mathrm{G} 1, \mathrm{G} 2)$ belong to the linguistic category green, with the category boundary between B1 and G1. The separation between the adjacent stimuli is equal. Discrimination of the cross-category stimulus pair (B1, G1) is faster and/or more accurate than discrimination of the within-category stimuli (B1, B2) or (G1, G2).

CP was first shown in speech perception. Liberman, Harris, Hoffman, and Griffith, (1957) tested participants on an $\mathrm{X}-\mathrm{AB}$ task. The participant's task was to indicate whether stimulus $\mathrm{X}$ is the same as stimulus A or B. The speech stimuli were from a continuum of sounds, varying in equal steps from one phoneme to another. Participants showed better discrimination when the target stimuli and test stimuli were from different phonemic categories than when they were from the same category. CP occurs for a range of perceptual phenomenon: for instance, perception of non-speech sounds (e.g., Cutting \& Rosner, 1974; Pastore, Li, \& Layer, 1990), perception of line length (Tajfel \& Wilkes, 1963), and also dimensions of face perception such as facial expressions (e.g., Etcoff \& Magee, 1992; Beale \& Keil, 1995; De Gelder, Teunisse, \& Benson, 1997; Campbell, Woll, Benson, \& Wallace, 1999; Bimler \& Kirkland, 2001; Campanella, Chrysochoos, \& Bruyer, 2001; Rossion, Shiltz, Laurence, Pirenne, \& Grommelinck, 2001; Levin \& Angelone, 2002).

Evidence for $\mathrm{CP}$ has also been reported on a wide range of colour perception tasks, for example, recognition memory and X-AB tasks (e.g., Uchikawa \& Shonida, 1996; Roberson, Davidoff, \& Braisby, 1999; Roberson \& Davidoff, 2000; Roberson, Davies, \& Davidoff, 2000; Pilling, Wiggett, Özgen, \& Davies, 2003), same-different tasks (e.g., Bornstein \& Korda, 1984; Boynton, Fargo, Olson, \& Smallman, 1989), similarity judgements (e.g., Laws, Davies, \& Andrews, 1995; Roberson et al., 1999), and target detection and visual search tasks (e.g., Franklin, Pilling, \& Davies, 2005; Daoutis, Franklin, Riddett, Clifford, \& Davies, 2006; Daoutis, Pilling, \& Davies, 2006). In the 2-X-AB task, a target stimulus (e.g., blue1) is presented followed by two test stimuli; one of the test stimuli is identical to the target and the other one (the foil) is different. The foil can be either from the same category as the target (e.g., blue2), or from a different category (e.g., green1). The task is to decide as fast as possible which of the test stimuli is identical to the target. The results showed that target identification was faster and/or more accurate for different category than same category foils. In the search task, a target stimulus is presented among other stimuli (distractors); the distractors can either be from the same category as the target (e.g., blue1 among blue2s) or from a different category to the target (blue1 among green1s). The task is to detect the location of the target as fast as possible. Detection of a target that is from a different category to the distractors is faster and/or more accurate than detection of a target from the same category as the distractors.

\section{Theories of CP}

Although CP has been reported in a wide range of studies, it is not clear what the origin and nature of this effect is. The degree to which language and perception contribute to the category effect has been extensively debated. Three main ideas have been emerged from the literature to account for the origin and nature effect of the CP: CP is "hardwired" into the visual system-It is innate; CP is due to verbal labelling; CP is due to perceptual change. 
Innate perceptual effect. The principal claim of the naturalistic theories (e.g., Bornstein, 1987; Snowden, 1987) is that, CP is an inborn, universal perceptual effect. Naturalistic theories are potentially supported by evidence for $\mathrm{CP}$ in young infants and in animals. Pre-linguistic participants perceive colour categorically before colour terms are learned. Bornstein, Kessen, and Weiskopf (1976) tested 4-month-old infants for colour categorisation. Infants were habituated to a target coloured stimulus, then they were shown a test coloured stimulus. The test stimulus either belonged to a different category, or to the same category, as the target stimulus. Although physical distances between stimuli were equal, infants dishabituated to the novel stimulus only when the test stimulus belonged to a different category to the habituated stimulus. Franklin and Davies (2004) also found evidence that infants had colour categories. Following familiarisation to one hue, infants only show novelty preference for a novel hue, if it comes from a different category to the familiarised hue. The findings are completely consistent with Bornstein et al.'s another study by Franklin et al. (2005), which tested 4-to-6-month-old infants for colour $\mathrm{CP}$ on a target detection task. Infants were shown a coloured target on a coloured background, with the target either from the same or different lexical category to the background. Infant eye movements to the target were recorded. Infants showed faster fixation of the target when the target and background were from different categories than from the same category. This findings provide strong evidence to support the naturalistic account of CP. Macaque monkey have also shown better discrimination for colours drawn from different categories than colours from the same category (Sandell, Gross, \& Bornstein, 1979). However, even if colour categories are found in pre-linguistic infants and in primates, colour categories need not necessarily be innate-Even pre-linguistic colour categories could be learnt.

Verbal labeling. Labelling theories argue that $\mathrm{CP}$ is driven by verbal labelling rather than by perception, and thus CP is not truly a perceptual phenomenon (e.g., Fujisaki \& Kwakshima, 1971; Kay \& Kempton, 1984; Roberson \& Davidoff, 2000). It is assumed that discrimination between perceptually different stimuli from different lexical categories is easier than stimuli from the same lexical category due to the different labels aiding discrimination. Thus, it is assumed that $\mathrm{CP}$ should not be shown when verbal labelling is absent. Evidence of the verbal account of the CP comes from cross-cultural and verbal interference studies. Several cross-cultural approach studies (e.g., Kay \& Kempton, 1984; Roberson et al., 2000; Daoutis et al., 2006) report that $\mathrm{CP}$ only occurs when the categories boundaries are marked linguistically. Another set of studies investigated the contribution of verbal labelling to CP by adding verbal interference to the colour task (e.g., Roberson \& Davidoff, 2000; Pilling, Wiggett, Özgen, \& Davies, 2003; Winawer, Witthoft, Frank, Wu, Wade, $\&$ Boroditsky, 2007). For instance, Roberson and Davidoff (2000) used a successive X-AB task. Participants were shown a target colour followed, after five seconds, by two test colours, the target and the foil. As described earlier, the foil was either from the same category as the target, or from a different category; the perceptual distance between the foil and the target was the same for both conditions. The participant's task was to decide which colour in the test pair was identical to the target. Three types of interference were used in the ISI (the interstimulus interval) period: visual interference, verbal interference and no interference. CP was found in the visual, and no interference conditions, but not in the verbal interference condition. The elimination of $\mathrm{CP}$ by verbal interference was assumed to be due to the interference impeding the retention of the name (verbal label), thus forcing the task to be done using visual memory alone. As no CP now occurs, this was taken as evidence that the benefit of $\mathrm{CP}$ is due to comparison of verbal labels enhancing cross-category comparisons, but not enhancing within-category comparisons. 
Perceptual change. Perceptual change theories (e.g., Harnad, Hanson, \& Lubin, 1991; Goldstone, Lippa, $\&$ Shiffrin, 2001) maintain that learning plays an important role in warping the representation of perceptual space. It is argued that learning to name a new stimulus dimension either in massed practice or in learning to distinguish the stimuli lexically leads to change in the representation of the stimulus dimension. Evidence from the perceptual learning experiment by Özgen and Davies (2002) has supported this idea. Participants were trained to learn a novel colour category such as yellowy-green $v s$. bluey-green. CP was then found around the recently learned category boundary.

\section{Aims of the Current Study}

The aim of the paper is to investigate whether the colour CP is still shown by participants from language, their reading direction is from right-to-left as in Arabic. All of the studies that have tested the CP of colour (e.g., Bornstein \& Korda, 1984; Boynton, Fargo, Olson, \& Smallman, 1989; Laws, Davies, \& Andrews, 1995; Uchikawa \& Shonida, 1996; Roberson et al., 1999; Roberson \& Davidoff, 2000; Roberson et al., 2000; Pilling et al., 2003; Franklin et al., 2005; Daoutis et al., 2006; Daoutis et al., 2006; Drivonikou, Kay, Regier, Ivry, Franklin, \& Davies, 2007a; Drivonikou, Davies, Franklin, \& Taylor, 2007b; Roberson, Park, \& Hanley, 2008; Tan, Chan, Kay, Khong, Yip, \& Luke, 2008; Liu et al., 2009) have examined the colour CP with left-to-right script readers. However, the influence of reading habits to perception has been shown in several studies (e.g., Eviatar, 1995, 1997; Farid \& Grainger, 1996; Prunet et al., 2000; Berent, 2002; Schwalm, Eviatar, Golan, \& Blumenfeld, 2003). This paper investigates the possible effect of habitual scanning on CP of colour, by examining participants from language who vary in their reading direction: right-to-left in Arabic. A preliminary study (Al-Rasheed, 2010) established the location of the azrock "blue" akhdar "green" boundary in Arabic. The Arabic blue-green category boundary was around 7.5BG which is in the same location as for English (Bornstein \& Monroe, 1980). CP of colour was then tested in the two samples using first, a target detection task (Experiment 1) and then grid search task (Experiment 2).

\section{Experiment 1: CP of Colour in a Target Detection Task}

\section{Introduction}

Experiment 1 was carried out to investigate whether habitual reading direction might affect the pattern of $\mathrm{CP}$ of colour. Arabic speakers, who read from right-to-left were tested. CP was investigated using a version of the target detection task where a circle target appeared on a differently coloured background at one of 12 locations around a central fixation point that, originally used by Franklin et al. (2005). The findings showed that $\mathrm{CP}$ of colour was independent of habitual reading direction and broadly replicated previous results (Bornstein \& Korda, 1984; Boynton et al., 1989; Laws et al., 1995; Uchikawa \& Shonida, 1996; Roberson et al., 1999; Roberson \& Davidoff, 2000; Roberson et al., 2000; Pilling et al., 2003; Franklin et al., 2005; Daoutis et al., 2006; Daoutis et al., 2006; Drivonikou et al., 2007a, 2007b; Roberson et al., 2008; Tan, Chan, Kay, Khong, Yip, \& Luke, 2008; Liu et al., 2009).

\section{Method}

Participants. Twenty participants were native Arabic-speaking. Post and undergraduates recruited from the student population of King Saud University. There were 10 males with a mean age of 24.8 years $(S D=$ 5.31), and 10 females, with a mean age of 22.7 years $(S D=4.92)$, with an age range from 18 to 34 years old. Based on self-report, all were right-handed and had normal colour vision, as indicated by the City University 
Test (Fletcher, 1980); all participated for course credit, and none of them were aware of the predictions of the experiment at the time of testing.

Stimuli and apparatus. Four colours were selected for this experiment as shown in Figure 2. Two stimuli were blue and two were green. They varied only in Munsell hue: 10G, 5BG, 10BG, and 5B, with value and chroma kept constant $(6 / 7)$. The separation between stimuli was 5 hue steps $(\Delta \mathrm{E} \sim 15)$. Their CIELUV coordinates $\left(\mathrm{u}^{*} \mathrm{v}^{*}\right)$ were: $-43.64,12.12 ;-45.65,-2.73 ;-44.83,-18.68 ; 39.62,32.97$. A Cambridge Research Instruments ColorCal was used to measure the International Commission on Illumination CIE co-ordinates. The colour stimuli were displayed on calibrated 17 inch CRT Sony Trinitron monitor.

$7.5 \mathrm{BG}$

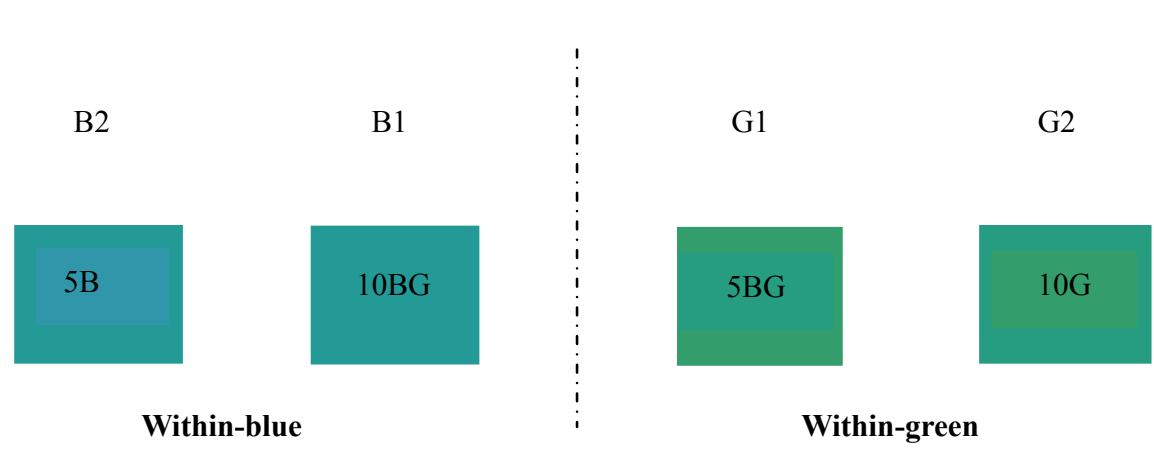

Cross-category

Figure 2. Illustration of the Munsell codes of the four stimuli used. B2 and B1 are blue and G1 and G2 are green. Adjacent colours are five hue steps apart. The line between B1 and G1 indicates the English blue-green boundary.

Procedure. The target was a circle of $3 \mathrm{~cm}$ diameter (visual angle $=3.22^{\circ}$ ) that appeared on a differently coloured background $(40 \times 30 \mathrm{~cm})$ at one of 12 locations around a central fixation point, half of them located in the left visual field and half in the right visual field (see Figure 3). Adjacent stimuli were paired, to give one within-category pair (green1-green2) and one between-category pair (green1-blue1). For each pair, on a given trial, one stimulus was used as the target and one stimulus as the background. However, across trials, each stimulus within a pair was used as the target half of the time and half of the time as the background.

There were three target-background pairs: two within-category (blue1-blue2 and green1-green2) and one between-category (blue1-green1). Within each pair, half the time, one was the target and the other the background, and on the other half of the trials, the relationship was reversed. There were 96 trials in total, consisted of 24 trials for the combinations of CP of colour (within-, between-). Trial order was randomised subject to the above constraints.

The participants were tested individually in a dark room, and were seated $60 \mathrm{~cm}$ away from the monitor and at eye-level to the centre of the monitor, with head restrained using a chin rest. Participants were instructed to click on the mouse button as quickly as possible when the target appeared on the monitor. The target could occur, at random, in any one of 12 locations arranged on a notional circle around the fixation cross. 


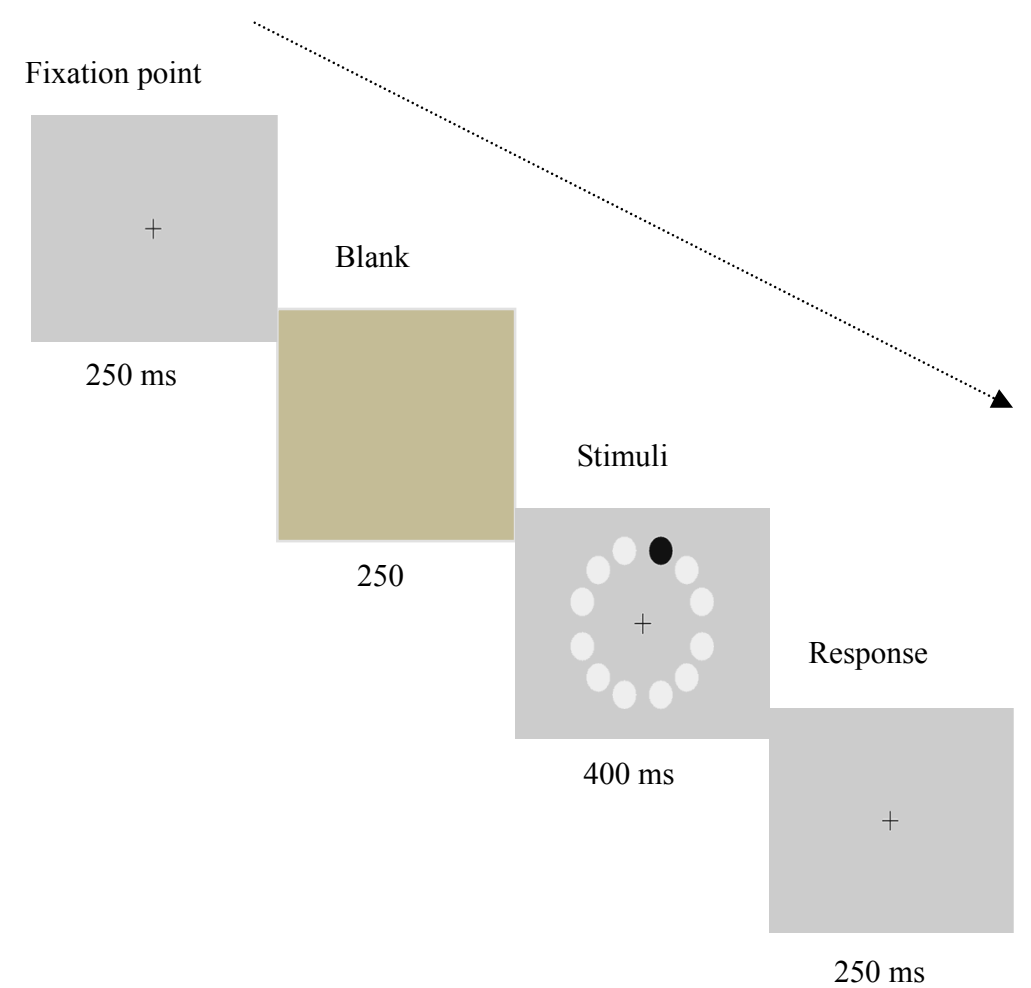

Figure 3. Example of the target detection task, the black dot shows the target, and the other 11 white circles indicate the possible target locations.

\section{Results}

As the main interest is in $\mathrm{CP}$ of colour, the author only reported the analysis of trials; the within-between category. Overall, there were only $1.2 \%$ errors; too small a rate to be usefully analysed. For each participant, the mean RT for each category (within-category and cross-category) was calculated. Figure 4 shows the mean RT across participants for each within-category and cross-category. A paired $t$-tests (2-tailed) showed that between-category (mean $(S D)=379(40.31) \mathrm{ms}$ ) was about $44 \mathrm{~ms}$ faster than within-category (mean $(S D)=$ $422(40.31) \mathrm{ms} ; t(19)=7.25, p<0.001)$.

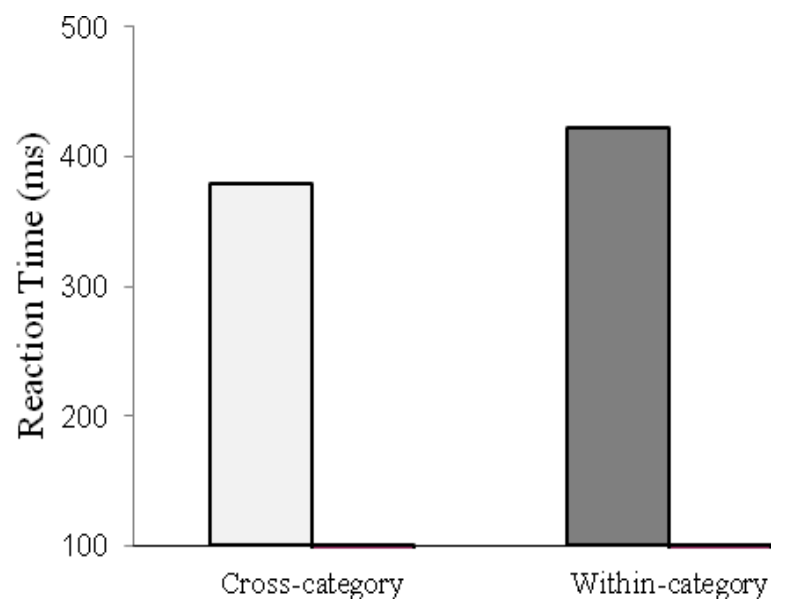

Figure 4. Mean response times ( $\mathrm{ms}+/-1 \mathrm{se}$ ) for correct trials for detecting of chromatic target on colour background. The data were averaged over the category (within/across). 


\section{Discussion}

The results mirrored the finding of previous studies (Bornstein \& Korda, 1984; Boynton et al., 1989; Laws et al., 1995; Uchikawa \& Shonida, 1996; Roberson et al., 1999; Roberson \& Davidoff, 2000; Roberson et al., 2000; Pilling et al., 2003; Franklin et al., 2005; Daoutis, Franklin et al., 2006; Daoutis, Pilling et al., 2006; Drivonikou et al., 2007a, 2007b; Roberson et al., 2008; Tan et al., 2008; Liu et al., 2009). Examined the colour $\mathrm{CP}$ with left-to-right script readers, discrimination of pairs of colour from different lexical categories (blue and green) was faster than pairs from the same lexical category (different shades of blue).

The aim of the experiment was to replicate the original finding $\mathrm{CP}$ of colour using a participants varied in habitual reading direction and in a task that varied in design and instructions to the tasks used in previous research. Participants were asked to decide as soon as possible when the target appeared on the coloured background. Response times showed the RT was significantly larger for the cross-category than for the within-category suggesting that $\mathrm{CP}$ of colour still occurs with participants who vary in their reading direction: right-to-left in Arabic. This result provides converging evidence that habitual scanning has no effect on $\mathrm{CP}$ of colour.

\section{Experiment 2: CP of Colour in Grid Search Task}

\section{Introduction}

The previous experiments in this paper investigated whether the $\mathrm{CP}$ of colour was independent of reading direction. The results showed that $\mathrm{CP}$ of colour was independent of habitual reading direction and broadly replicated previous results (e.g., Bornstein \& Korda, 1984; Boynton et al., 1989; Laws et al., 1995; Uchikawa \& Shonida, 1996; Roberson et al., 1999; Roberson \& Davidoff, 2000; Roberson et al., 2000; Pilling et al., 2003; Franklin et al., 2005; Daoutis et al., 2006; Daoutis et al., 2006; Drivonikou et al., 2007a, 2007b; Roberson et al., 2008; Tan et al., 2008; Liu et al., 2009) have examined the colour CP with left-to-right script readers. However, the influence of reading habits to perception has been shown in several studies (e.g., Eviatar, 1995, 1997; Farid \& Grainger, 1996; Prunet et al., 2000; Berent, 2002; Schwalm, Eviatar, Golan, \& Blumenfeld, 2003). Most tests of CP of colour have used one or other of these tasks, and it is important to establish that the effect is independent of the detailed methods used. Here, the author investigated a number of distractors affect the CP of colour.

Most of the studies that tested the CP of colour used tasks similar in design Franklin et al. (2005). In this experiment (Experiment 2), the number of distracters was enlarged (35 distracters) to test whether search time was independent of the number of distractors, indicating "pop-out" (Treisman \& Gelade, 1980), or that search was "efficient" (Wolfe, 1994). If search was not efficient, then the pattern of CP of colour might interact with the number of distracters.

\section{Method}

Participants. Twenty participants (10 male and 10 female) took part in the grid search task. They spoke Arabic as their first language and most were undergraduate students at King Saud University. None of them have participated in the first experiment. Based on self-reports, all were right-handed and had normal colour vision, as indicated by the City University Test (Fletcher, 1980). Their ages ranged from 17 to 35 years. Male, mean age was 24.3 years $(S D=5.29)$ and females, with a mean age of 20 years $(S D=6)$. Few of the participants participated for course credit and a most volunteered. 
Stimuli and apparatus. Three colour stimuli were used in this experiment as shown in Figure 4: one green $(5 \mathrm{BG})$ and two blues $(10 \mathrm{BG}$ and $5 \mathrm{~B}$; Value and Chroma $=6 / 8)$. The separation between adjacent stimuli was five Munsell hue steps (AE 15). Their CIELUV coordinates $\left(\mathrm{u}^{*} \mathrm{v}^{*}\right)$ were $-45.65,-2.73 ;-44.83,-18.68$; -39.62, -32.97; all at $\mathrm{L}^{*}=61.70$; a Cambridge Research Systems, ColorCal colorimeter was used to measure the CIE co-coordinates and they were displayed on a 17-inch CRT model GDM-F520.

Procedure. Adjacent stimuli were paired, to form one within-category pair (blue1-blue2) and one between-category pair (blue1-green1). For each pair, one stimulus was the target and the other stimulus was used for the distractors, with both stimuli in a pair appearing equally often as distractors. The target for all trials was always blue and the distractors were randomly switched between "within" (blue) and "across" (green). There were equal numbers of trials for each combination of category (within- or between-) and visual field (LVF or RVF) and the order of trials was randomised across these four conditions. In addition, target location was randomised across trials with the constraint that the target appeared equally often to the left and right of fixation. Stimuli were shown as $2.5 \mathrm{~cm}$ squares with $5 \mathrm{~mm}$ gaps between adjacent locations, appearing in locations specified by a $6 \times 6$ square grid on the display (see Figure 5). The target appeared amongst 35 distractors on a grey background $\left(19.47 \mathrm{~cd} / \mathrm{m}^{2}, 0.336,0.344\right)$ (see Figure 6).

$7.5 \mathrm{BG}$

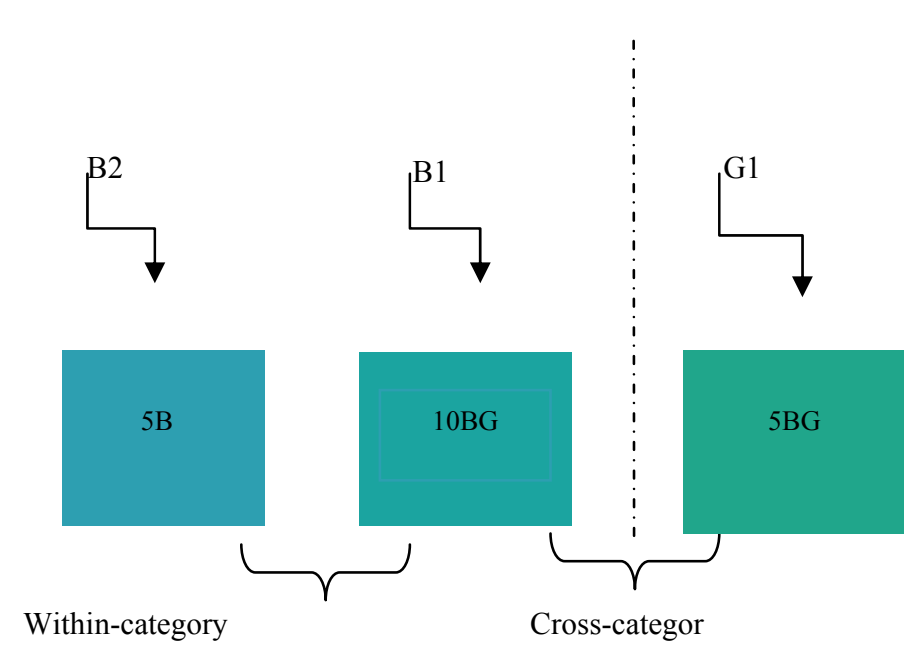

Figure 5. Illustration of the Munsell codes of the three stimuli used. Stimuli B1 and B2 are from the same category, while stimulus G1 belongs to a different category. B1-B2 and B1-G1 differ by 5 Munsell Hue steps. The line between B1 and G1 indicates the Arabic blue-green boundary.

The experiment began with a fixation cross which remained for $100 \mathrm{~ms}$ to alert the participants that the trial was beginning. Then the test display followed and remained on screen for $200 \mathrm{~ms}$. The next trial began when the participants had responded. There were 64 trials. Participants were given 15 practice trials before starting the experiment, and they took about seven minutes to complete the task.

The participants were tested individually in a dark room and sat with their head position constrained by a chin-rest, so that eye-level was at the centre of the monitor, with a viewing distance of $60 \mathrm{~cm}$. Participants were informed that they would be presented with a target stimulus among a number of 35 distractors and their task was clicking the mouse button as soon as possible when they see the target (different colour than the other 35 distractors). 


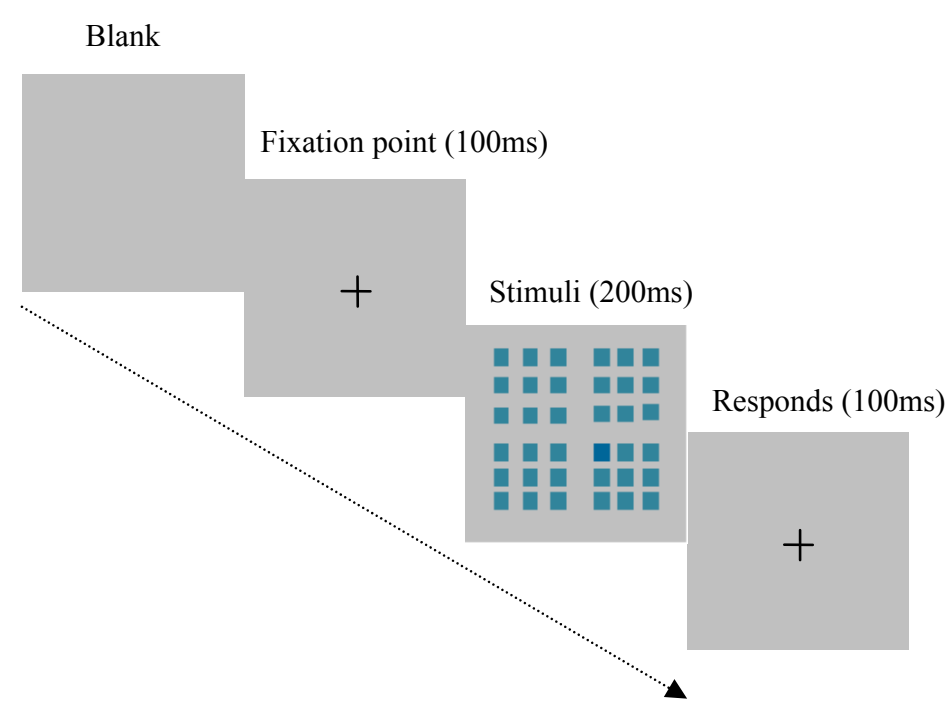

Figure 6. Example of the grid task. The blue square shows the target, and the other green squares indicate the distractors.

\section{Results}

The percentage of incorrect trials was calculated for each subject, for each combination of category (within/cross). A paired sample $t$-tests (2-tailed) showed that there was significant effect on the number of incorrect trials between-category (mean $(S D)=3.00(1.56)$ ) was smaller by 1.90 trials than within-category $($ mean $(S D)=4.90(1.56) ; t(19)=4.25, p<0.001)$. Then, for each participant, median RTs for correct trials for each category (within category and cross category) was calculated. Figure 7 shows the mean RT across participants for each within category and cross category. A paired sample $t$-tests (2-tailed) showed that between-category (mean $(S D)=467(46.19) \mathrm{ms})$ was about $49 \mathrm{~ms}$ faster than within-category (mean $(S D)=$ $560(91.68) \mathrm{ms} ; t(19)=7.28, p<0.001)$.

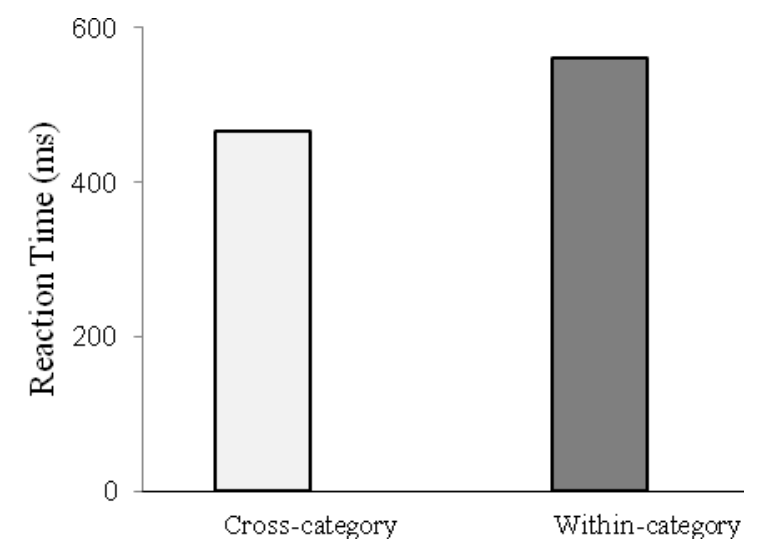

Figure 7. Mean response times (+/-1se) for each combination of category and visual field.

\section{Discussion}

The characteristic pattern of $\mathrm{CP}$ of colour was found again in this study, there was clearly category effect between-category was about $49 \mathrm{~ms}$ faster than within-category. In addition, there was no suggestion that the number of distractors affected RTs, indicative of pop-out or efficient search, nor any suggestion that the number of distractors affected the pattern of $\mathrm{CP}$ of colour. These data provide further support for the bias in colour $\mathrm{CP}$. 


\section{General Desiccation}

This paper reported two experiments of investigations into aspects of the "Psychology of Colour". These investigations all relate to long standing questions about the origin, nature, and interaction of colour language, perception, and cognition. The main aim of investigation is to contribute to the debate about the origin of categorical perception of colour by establishing whether categorical perception of colour is invariant across reading direction and tasks. This section summarises the findings for each of two investigations, whilst also highlights the contribution to the debates and identifies the need for further research.

The first investigation (Experiment 1) was into factors affecting the categorical colour perception, explored how universal and robust a $\mathrm{CP}$ of colour is by establishing whether the $\mathrm{CP}$ of colour was affected by reading direction as the influence of habitual scanning on perception which has been shown in several studies (e.g., Eviatar, 1995, 1997; Schwalm et al., 2003; Farid \& Grainger, 1996; Prunet et al., 2000; Berent, 2002). Research on the blue-green colour CP was conducted in Experiment 1 by using a version of ranklin, Drivonikou, Bevis, Davies, Kay, Regier (2008) target detection task. Despite the differences in reading direction for Arabic sample, still right-to-left script readers samples showed effectively the same pattern of results. They discriminated pairs of colours from different lexical categories significantly faster than pairs from the same lexical categories (CP). Experiment 2 further tested the robustness of $\mathrm{CP}$ of colour by testing Arabic samples with a new colour task. The effect has previously been tested for adults using target detection tasks where participants are required to indicate whether a target appeared on colour background (Franklin et al., 2008). Experiment 2 experiments used variant task, a grid search task that varied the number of distractors (35 distractors). The characteristic pattern of $\mathrm{CP}$ of colour was found on this tasks, showing a trend for a $\mathrm{CP}$ of colour bias and a significant $\mathrm{CP}$ effect.

These experiments confirmed that readers of right-to-left scripts, such as Arabic, show the same pattern of lateralisation as readers of left-to-right scripts, such as English. Habitual scanning direction seems to have no effect on how colour CP is categorised.

\section{References}

Al-rasheed, A. S. (2010). Colour Cognition in Arabic and English Speakers. Doctoral thesis, University of Surrey.

Androulaki, A., Natalia, G. P., Christos, M., Julio, L. J., Kenny, C., Davies, B., J. M. \& Keil, F. C. (1995). Categorical effects in the perception of faces. Cognition, 57, 217-239.

Beebe-Center, J. G. (1932). The psychology of pleasantness and unpleasantness. New York: Van Nostrand.

Beke, L., Kutas, G., Kwak, Y., Young Sung, G., Park, D. S., \& Bodrogi, P. (2008). Color preferences of aged observers compared to young observers. Color Research \& Application, 33(5), 381-394.

Berent, I. (2002). Identity avoidance in the Hebrew lexicon: Implications for symbolic accounts of word formation. Brian and Language, 81, 326-341.

Berlin, B., \& Kay, P. (1969). Basic color terms: Their universality and evolution. Berkeley \& Los Angeles: University of California Press.

Bimler, D., \& Kirkland, J. (2001). Categorical perception of facial expressions of emotion: Evidence from multidimensional scaling. Cognition and Emotion, 15(5), 633-658.

Bjersted, A. (1960). Warm-cool color preferences as potential personality indicators: Preliminary note. Perception and Motor Skills, 10, 31-34.

Bornstein, M. H. (1975). Qualities of color vision in infancy. Journal of Experimental Child Psychology, 19, 401-419.

Bornstein, M. H. (1987). Infants are trichromats. Journal of Experimental Child Psychology, 21, 425-445.

Bornstein, M. H., Kessen, W., \& Weiskopf, S. (1976). Color vision and hue categorization in young infants. Journal of Experimental Psychology: Human Perception and Performance, 1, 115-129. 
Bornstein, M. H., \& Korda, N. (1984). Discrimination and matching within and between hues measured by reaction times: Some implications for categorical perception and levels of information processing. Psychological Research, 46, 207-222.

Bornstein, M. H., \& Monroe, M. D. (1980). Chromatic information processing: Rate depends on stimulus location in the category and psychological complexity. Psychological Research, 42, 213-225.

Boynton, R. M., Fargo, L., Olson, C. X., \& Smallman, H. S. (1989). Category effect in color memory. Color Research and Application, 14(5), 229-234.

Campanella, S., Chrysochoos, A., \& Bruyer, R. (2001). Categorical perception of facial gender information: Behavioural evidence and the face-speech metaphor. Visual cognition, 8(2), 237-262.

Campbell, R., Woll, B., Benson, P., \& Wallaca, S. B. (1999). Categorical perception of face actions: Their role in sign language in communicative facial displays. Quarterly Journal of Experimental Psychology, 52(1), 67-95.

Cowan, J. M. (1974). A dictionary of modern written Arabic. London: Macdonald \& Evans.

Cutting, J. E., \& Rosner, B. S. (1974). Categories and boundaries in speech and music. Perception and Psychophysics, 16, 564-570.

Daoutis, C. A., Franklin, A., Riddet, A., Clifford, A., \& Davies, I. R. L. (2006a). Categorical effects in children's colour search: A cross-linguistic comparison. British Journal of Developmental Psychology, 24(2), 373-400.

Daoutis, C. A., Pilling, M., \& Davies, I. R. L. (2006b). Categorical effects in visual search of colour. Visual Cognition, 14, 229-234.

De Gelder, B. L. M. F., Teunisse, J. P., \& Benson, P. J. (1997). Categorical effects of facial expressions: Categorical and their internal structure. Cognition and Emotion, 11(1), 1-23.

Drivonikou, G. V., Davies, I. R. L., Franklin, A., \& Taylor, C. (2007b). Lateralisation of colour categorical perception: A cross-cultural study. Perception, 36, ECVP Abstract Supplement.

Drivonikou, G. V., Kay, T., Regier, R. B., Ivry, A. L., Franklin, A., \& Davies, I. R. L. (2007a). Further evidence that Whorfian effects are stronger in the right visual field than the left. Proceeding of the National Academy of Sciences, 104, 1097-1102.

Eichstedt, J. A. (1997). Infants' metaphorical knowledge about gender (Unpublished master's thesis, Concordia University, Montreal, Quebec).

Etcoff, N. L., \& Magee, J. J. (1992). Categorical effects in the perception of faces. Cognition, 57(3), 217-239.

Eviatar, Z. (1995). Reading direction and attention: Effects on lateralized ignoring. Brian and Cognition, 29, 137-150.

Eviatar, Z. (1997). Language experience and right hemisphere task: The effects of scanning habits and multilingualism. Brian and Cognition, 58, 157-173.

Eysenck, H. (1941). A critical and experimental study of colour preference. American Journal of Psychology, 54, $385-391$.

Farid, M., \& Grainger, J. (1996). How initial fixation position influences visual word recognition: A comparison of French and Arabic. Brian and Language, 53, 351-368.

Fletcher, R. (1980). The City University Colour Vision Test. Keeler Ltd. Windsor, Berks.

Franklin, A., \& Davies, I. R. L. (2004). New evidence for infant colour categories. British Journal of Developmental Psychology, 22, 349-377.

Franklin, A., Drivonikou, G. V., Bevis, L., Davies, I. R. L., Kay, P., \& Regier, T. (2008). Categorical perception of color is lateralised to the right hemisphere in infants, but to the left hemisphere in adults. Proceedings of the National Academy of Sciences, 105, 3221-3225.

Franklin, A., Pilling, M., \& Davies, I. R. L. (2005). The nature color categorisation: Evidence from eye-movements on a target detection task. Journal of Experimental Child Psychology, 91, 227-248.

Fujisaka, H. \& Kawashima, T. (1971). On the modes and hearing mechanisms of speech perception. Annual Report of the Engineering Research Institute, Vol., 28, Faculty of Engineering, University of Tokyo.

Gilbert, A. L., Regier, T., Kay, P., \& Ivry, R. B. (2006). Whorfian hypothesis supported in the right visual field but not the left. Proceeding of the National Academy of Sciences, 103, 489-494.

Goldstone, R. L., Lippa, Y., \& Shiffrin, R. M. (2001). Altering object representations through category learning. Cognition, 78, 27-43.

Harnad, S. (1987). Categorical perception: The groundwork of cognition. New York: Cambridge University Press.

Harnad, S., Hanson, S. J., \& Lubin, J. (1991). Categorical perception and the evolution of supervised learning in neural nets. In D. W. Powers, \& L. Reeker, (Eds.), Working papers of the AAAI spring symposium on machine learning of natural language and ontology (pp. 65-74). Presented at Symposium on Symbol Grounding: Problems and Practice, Stanford University, March 1991. 
Kay, P., \& Kempton, W. (1984). What is the Sapir-Whorf hypothesis? American Anthropologist, 86, 65-79.

Laws, G., Davies, I., \& Andrews, C. (1995). Linguistic structure and non-linguistic cognition: English and Russian blues compared. Language and Cognitive Processes, 10(1), 59-94.

Levin, D. T., \& Angelone, B. L. (2002). Categorical perception of race. Perception, 31(5), 567-578.

Liberman, A. M., Harris, K. S., Hoffman, H. S., \& Griffith, B. C. (1957). The discrimination of speech sounds within and across phoneme boundaries. Journal of Experimental Psychology, 45, 358-368.

Liu, Q., Li, H., Campos, J. L., Wang, Q., Zhang, Y., Qiu, J., Zhang, Q., \& Sun, H. (2009). The N2pc component in ERP and lateralization effect of language on color perception. Neuroscience Letters, 454, 58-61.

Özgen, E., \& Davies, I. R. (2002). Acquisition of categorical color perception: A perceptual learning approach to the linguistic relativity hypothesis. Journal of Experimental Psychology, 131(4), 477-493.

Pastore, R. E., Li, X., \& Layer, J. K. (1990). Categorical perception of non-speech chirps and bleats. Perception and Psychophysics, 48(2), 151-156.

Pilling, M., Wiggett, A., Özgen, E., \& Davies, I. R. L. (2003). Is color "categorical perception" really perceptual? Memory and Cognition, 31(4), 538-551.

Prunet, J. F., Beland, R., \& Idrissi, A. (2000). The mental representation of semitic word. Linguistic Inquiry, 31, 609-648.

Roberson, D., \& Davidoff, J. (2000). The categorical perception of colors and facial expressions: The effect of verbal interference. Memory and Cognition, 28(6), 977-986.

Roberson, D., Davidoff, J., \& Braisby, N. (1999). Similarity and categorisation: Neuropsychological evidence for a dissociation in explicit tasks. Cognition, 71, 1-42.

Roberson, D., Davies, I. R. L., \& Davidoff, J. (2000). Color categories are not universal: Replications and new evidence from a stone-age culture. Journal of Experimental Psychology: General, 129, 369-398.

Roberson, D., Park, H., \& Hanley, R. J. (2008). Categorical perception of colour in the left and right visual field is verbally mediated: Evidence from Korean. Cognition, 107(2), 752-762.

Rossion, B., Schilitz, C., Laurence, R., Pirenne, D., \& Grommelinck, M. (2001). How does the brain discriminate familiar and unfamiliar faces?: A PET study of face categorical perception. Journal of Cognitive Neuroscience, 13, 1019-1034.

Sandell, J. H., Gross, C. C., \& Bornstein, M. H. (1979). Color categories in macaques. Journal of Comparative and Physiological Psychology, 93(4), 626-625.

Schwalm, N. D., Eviatar, Z., Golan, Y., \& Blumenfeld, Y. (2003). The effect of reading direction habit on numerical processing. Proceeding of the Human Factors and Ergonomics Society 47th Annual Meeting.

Snowden, C. T. (1987). A naturalistic view of categorical perception. In S. Harnad (Ed.), Categorical perception: The groundwork of cog-nition (pp. 332-354). Cambridge: Cambridge University Press.

Tajfel, H., \& Wilkes, H. (1963). Classification and quantitative judgment. British Journal of Psychology, 54, 101-114.

Tan, L. H., Chan, A. H. D., Kay, P., Khong, P., Yip, L. K. C., \& Luke, K. (2008). Language affects patterns of brain activation associated with perceptual decision. Journal of Experimental Psychology: Human Perception and Performance, 105(10). 4004-4009.

Treisman, A., \& Gelade, G. (1980). A feature integration theory of attention. Cognitive Psychology, 12, 97-136.

Uchikawa, K., \& Shonida, H. (1996). Influence of basic color categories on color memory discrimination. Color Research and Application, 21(6), 430-439.

Winawer, J., Witthoft, N., Frank, M., Wu, L., Wade, A., \& Boroditsky, L. (2007). Russian blues reveal effects of language on color discrimination. Proceedings of the National Academy of Sciences, 104, 7780-7785.

Wolfe, J. (1994). Guided Search 2.0: A revised model of visual search. Psychonomic Bulletin and Review, 1, $202-238$. 